\title{
SEISMIC ISOLATION OF BRIDGES USING THE PRINCIPLE OF ELECTROMAGNETIC ATTRACTION AND REPULSION
}

\author{
Silviu Alexandru Constantinescu, PhD Student, Technical University of Civil Engineering \\ Bucharest, e-mail: silviu.a.constantinescu@gmail.com \\ Ionuț Radu Răcănel, Assoc. Prof., Technical University of Civil Engineering, Strength of \\ Materials, Bridges and Tunnels Department, e-mail: ionut@cfdp.utcb.ro
}

\section{Rezumat}

Articolul prezintă o metodă nouă de izolare seismică, bazată pe principiul atracției și respingerii electromagnetice și a controlului în timp real al forţei de frecare dintre doi electromagneți. Cei doi electromagneți sunt utilizați în combinație cu un sistem auxiliar de amortizare și disipare a energiei cinetice din suprastructură ce este compus dintr-un inel de neopren de $10 \mathrm{~mm}$ grosime și două suprafețe metalice pulverizate cu nitrură de siliciu $\mathrm{Si}_{3} \mathrm{~N}_{4}$. Întregul sistem utilizează accelerometre triaxiale încastrate în culee, acumulatori de mare amperaj și o unitate de control automat. Izolatorul a fost dezvoltat special pentru un pod cu grinzi din beton armat cu o singură deschidere de $36 \mathrm{~m}$, utilizând analize numerice timehistory, atât electromagnetice cât și structurale. Articolul prezintă avantajele utilizării unui astfel de sistem de izolare seismică prin comparație cu sistemele pasive utilizate în prezent, precum și rezultatele importante obținute în termeni de eforturi secționale reduse în infrastructura podului simultan cu reducerea deplăsarilor relative a suprastructurii.

\section{Cuvinte cheie: electromagnetism, izolare seismică, modelare numerică, time-history}

\section{Abstract}

This paper presents a new type of seismic isolator that uses the principle of electromagnetic attraction and repulsion, to control the friction force between two electromagnets during earthquakes. The two electromagnets are used in conjunction with a secondary high friction dissipating and damping mechanism composed from a $10 \mathrm{~mm}$ thick neoprene ring layer and two steel surfaces coated with Si3N4 that are used to dissipate the kinetic energy in the bridge deck at some maximum ground accelerations. The isolator utilizes tri-axial accelerometers embedded in the abutments, high current rechargeable batteries and an automated controlling unit. The presented isolator was developed specifically for a concrete bridge deck with a span of 36 meters and simple supported on two abutments, using time history electromagnetic and structural analyses. The paper presents the advantages of using this active seismic isolation system, compared to classical passive devices and the important results obtained in terms of decreasing internal forces on the substructure elements cross sections together with the reduction of relative displacements between the two electromagnets. 
Keywords: electromagnetism, seismic isolation, numerical modelling, time-history analysis

\section{INTRODUCTION}

Evaluation of seismic intensity using current design codes presents a degree of uncertainty due to numerous factors that can affect seismic actions. Those uncertainties and disastrous effects of seismic actions, combined with the considerations of a fixed base and limited usage of structural elements of bridges into the elastic domain, determined a continuous research for more performant seismic protection systems in this field. Such a performant method is represented by the base isolation method that evolved and changed the behavior of civil engineering structures in the last 50 years. It can be said that it is the most performant method from both cost and structural points of view.

The dominant seismic isolators that are currently used for bridge structures are the friction pendulum, viscous dampers or elastomeric bearings with metallic insertions. All these isolators have a specific working domain and the computed positive effects on the structure could diminish significantly or they could even turn into negative effects if the frequencies or accelerations of seismic action migrates out of the design spectra domain (Figure 1).

Due to their upper limit of seismic energy dissipation, the neoprene and friction pendulum isolators are based on minimizing the induced accelerations in the bridge deck by increasing the oscillating period. This represents a disadvantage for bridge structures due to unwanted increased displacements of the bridge deck, relative to infrastructure.

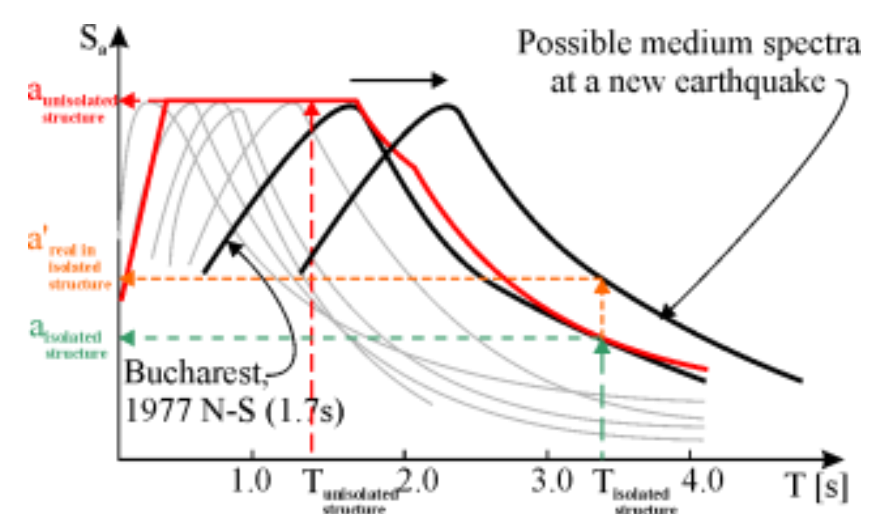

Figure 1. Seismic action migration, out of considered design spectra

By comparison with passive isolators, the proposed seismic isolator described in this paper has a much higher adaptability to seismic action. Its 
response is not influenced by the frequencies composition of the earthquake and it can also control the relative displacements of the bridge deck at any moment in time, during seismic event.

The active isolator was designed specifically to handle a vertical reaction of $1200 \mathrm{kN}$, force produced by a $7200 \mathrm{kN}$ and $36 \mathrm{~m}$ span concrete bridge deck for one of its 6 supports.

\section{DESCRIPTION OF THE PROPOSED ELECTROMAGNETIC SEISMIC ISOLATION SYSTEM}

The entire system is composed from electromagnetic seismic isolators, high current rechargeable batteries, 3D accelerometers and a control unit. An isolator is composed from two electromagnets whose magnetic fields are adjusted in real time by the control unit installed below the supporting benches of the abutments (Figure 2).

The working principle is based on Faraday's law of induction and Maxwell's equations. Faraday's law says that the magnetic lines of force starts and end on electric charges, are not intersecting and their spacing indicates the intensity of the magnetic flux. Depending on the intensity and direction of magnetic flux at the contact interface between the two electromagnets, we obtain two resultant forces that tends to separate or attract the two electromagnets. These forces are resulted by integrating over the volume the resulted mass forces caused by magnetic flux.

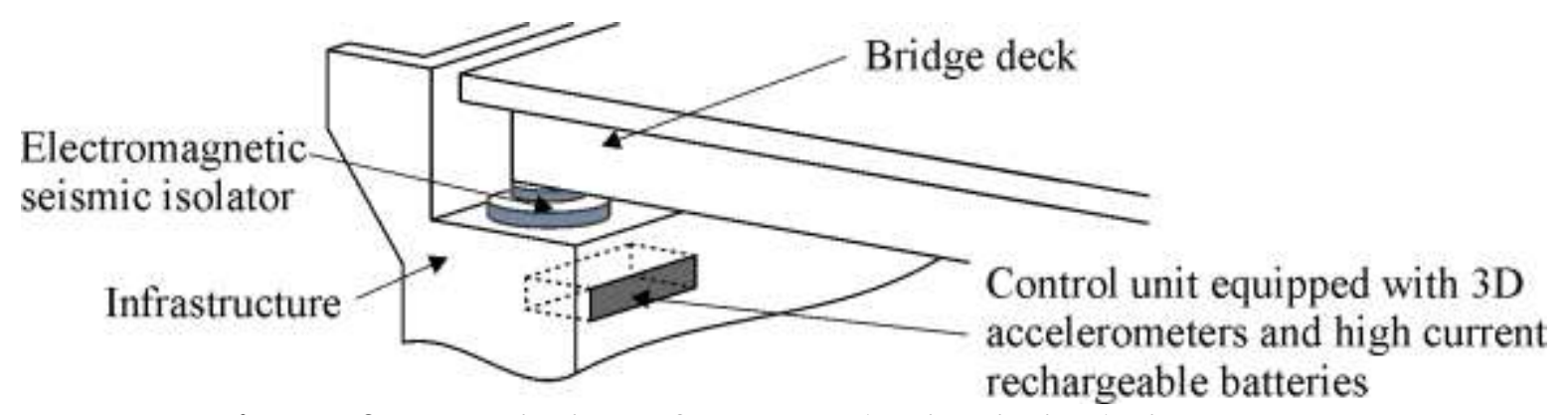

Figure 2. Description of proposed seismic isolation system

This phenomen of attraction and repulsion and other electromagnetic behaviors, can be described down to atomic level by Maxwell's equations ((1) to (4)).

$$
\nabla \cdot E=\frac{\rho}{\epsilon_{0}}
$$




\section{ROMANIAN JOURNAL OF TRANSPORT INFRASTRUCTURE}

$$
\begin{aligned}
& \nabla \cdot B=0 \\
& \nabla \times E=\frac{\partial B}{\partial t} \\
& \nabla \times B=\mu_{0} \cdot j+\mu_{0} \cdot \epsilon_{0} \cdot \frac{\partial E}{\partial t}
\end{aligned}
$$

Where: $E(r, t)=$ intensity of electric field;

$\mathrm{B}(\mathrm{r}, \mathrm{t})=$ intensity of magnetic field;

$\rho(\mathrm{r}, \mathrm{t})=$ density of electric field;

$\mathrm{j}(\mathrm{r}, \mathrm{t})=$ density of electric current;

$\epsilon_{0}=8,8542 \cdot 10^{-12} C^{2} N^{-1} m^{-2}=$ electric permittivity in vacuum;

$\mu_{0}=4 \pi \cdot 10^{-7} N A^{-2}$ is the magnetic permittivity in vacuum.

Thus, by adjusting the intensities of magnetic fields in the two electromagnets, the attraction and repulsion forces can be controlled and so the friction force $F_{f}$ and compressive force $F_{n}$ at the contact interface (Figure 3, Figure 4). From classical mechanics, the friction force is given by (5).

$$
F_{f}=\mu \cdot F_{n}
$$

where $\mu$ represents the friction coefficient and $F_{n}$ represents the compression force perpendicular to the contact surface between the two bodies.

The friction coefficient is measured experimentally for different materials and varies as a function of the relative motion between the two bodies in contact (Figure 3). At relative rest, $\mu=\mu_{s}$ is called a static friction coefficient and for two bodies in relative motion, $\mu=\mu_{k}$ is called a dynamic friction coefficient.

The transition from static to dynamic friction is performed through an exponential function of a decay parameter $\beta$ and relative speed between the two surfaces in contact.
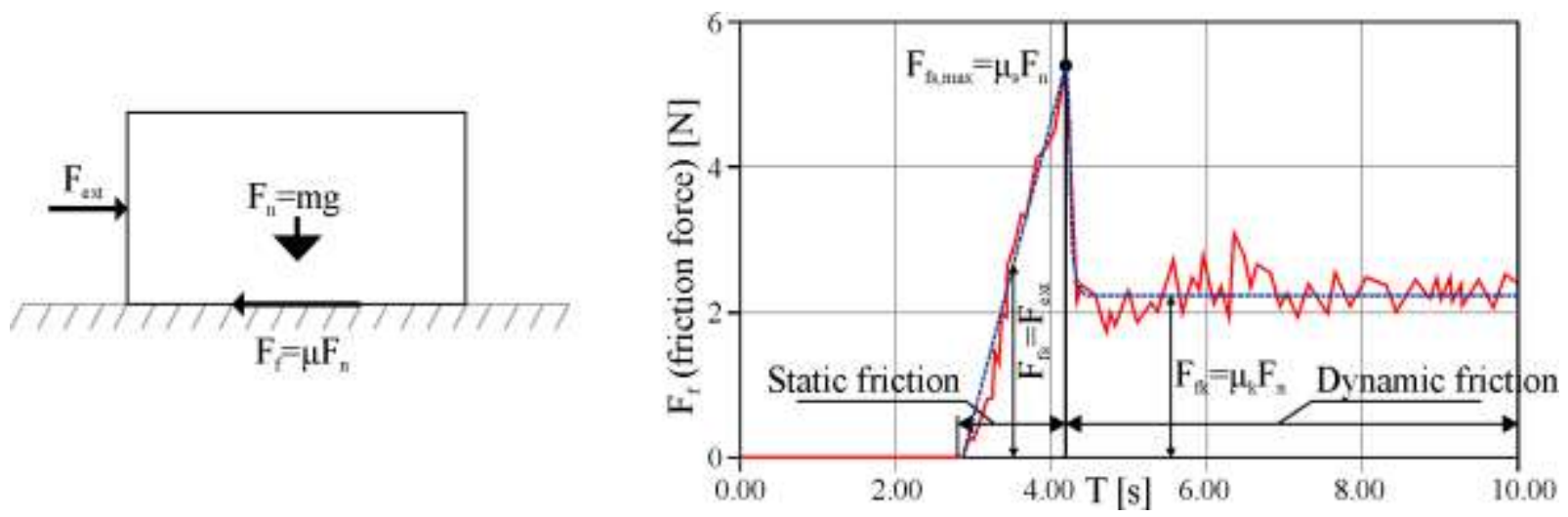

Figure 3. Static and dynamic friction force 


\section{ROMANIAN JOURNAL OF TRANSPORT INFRASTRUCTURE}

Silviu Alexandru Constantinescu, Ionuț Radu Răcănel

Seismic isolation of bridges using the principle of electromagnetic attraction and repulsion
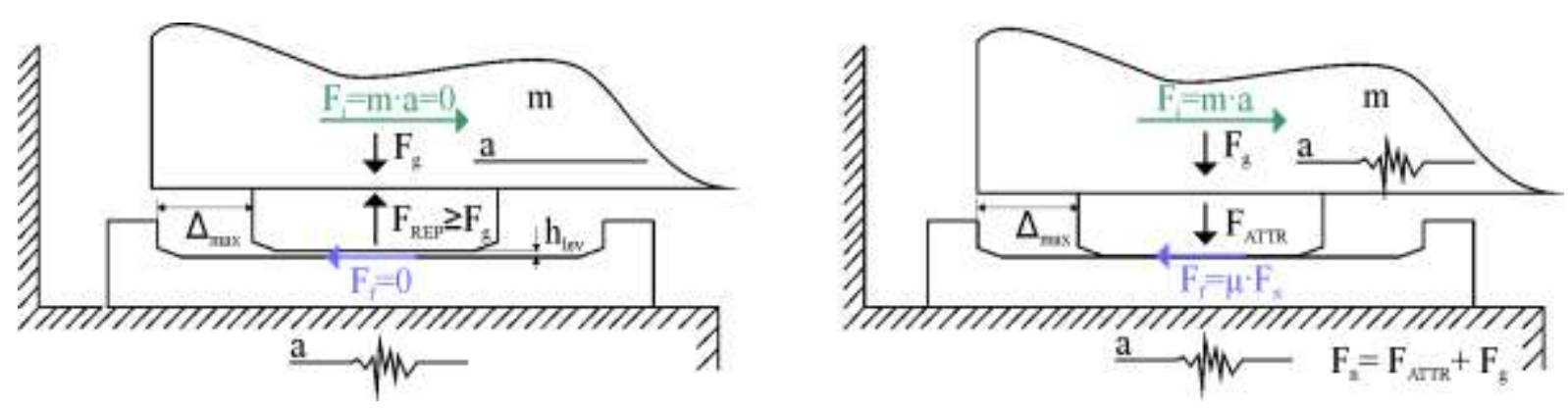

Figure 4. Friction control by electromagnetic attraction and repulsion

For the proposed seismic isolator, if the electromagnetic repulsion force $F_{R E P}$ is greater than the vertical loads transferred by the upper electromagnet $F_{g}$, for a very thin spacing it can be considered that the upper electromagnet will levitate at a relative height $h_{l e v}$, and the friction force $F_{f}$ will equal zero. On the other hand, if the attraction force $F_{\text {ATTR }}>0$, the compressive force between the two electromagnets $F_{n}$ can raise up to a value that's three times bigger than the compressive force given by the transmitted vertical load from the upper electromagnet.

There are multiple possibilities of utilizing this seismic isolation principle. In the current paper only one method is analyzed and that is by sequentially discharging the kinetic energy accumulated in the bridge deck by controlling the friction between the two electromagnets but also through a supplementary friction plane and damping mechanism that limits the dynamic shocks in the infrastructure.

When the seismic action is sensed by the 3D accelerometers, the repelling forces in the two electromagnets (EM1 top and EM2 bottom) are ramped up to a quasi-levitation state $F_{f} \sim 0$. This is required to have a small friction coefficient in the first friction plane at initialization of seismic event (Figure 5).

During the seismic event, while the acceleration in the supporting bench increase, the friction between EM1 and EM2 is proportionally increased, until the derivative of the acceleration function change its sign and the acceleration starts to decrease. At this moment, the friction force at the top friction plane (F1) is increased rapidly up to a maximum value or specific value that will result in fixing the two electromagnets and discharge the remanent kinetic energy in the bridge deck into the bottom electromagnet by activating the friction force in the second friction plane (F2).

For optimal function, when a local maximum of acceleration function is reached, the value of the friction force F1 should be very close to the value of F2. If it weren't for a secondary friction plane, the forces on the infrastructure 


\section{ROMANIAN JOURNAL OF TRANSPORT INFRASTRUCTURE}

Silviu Alexandru Constantinescu, Ionuț Radu Răcănel

elements cross sections would be biger than utilizing simple classic bearings without any seismic isolation capabilities. For the friction force F2 to be exceeded only when reaching the max friction force F1, the two surfaces in contact from the second friction plane must have an increased friction coefficient.

To obtain a high friction coefficient, the steel surfaces can be pulverized with a thin $100 \mu$ silicon nitride (Si3N4) through a High-Velocity Pulsed Plasma Spraying [1]. Utilizing such a method, high friction coefficients could be achieved in the order of 1.1 to 1.4. For the numerical analyses a static friction coefficient of 1.3 and a dynamic friction of 0.9 were chosen.
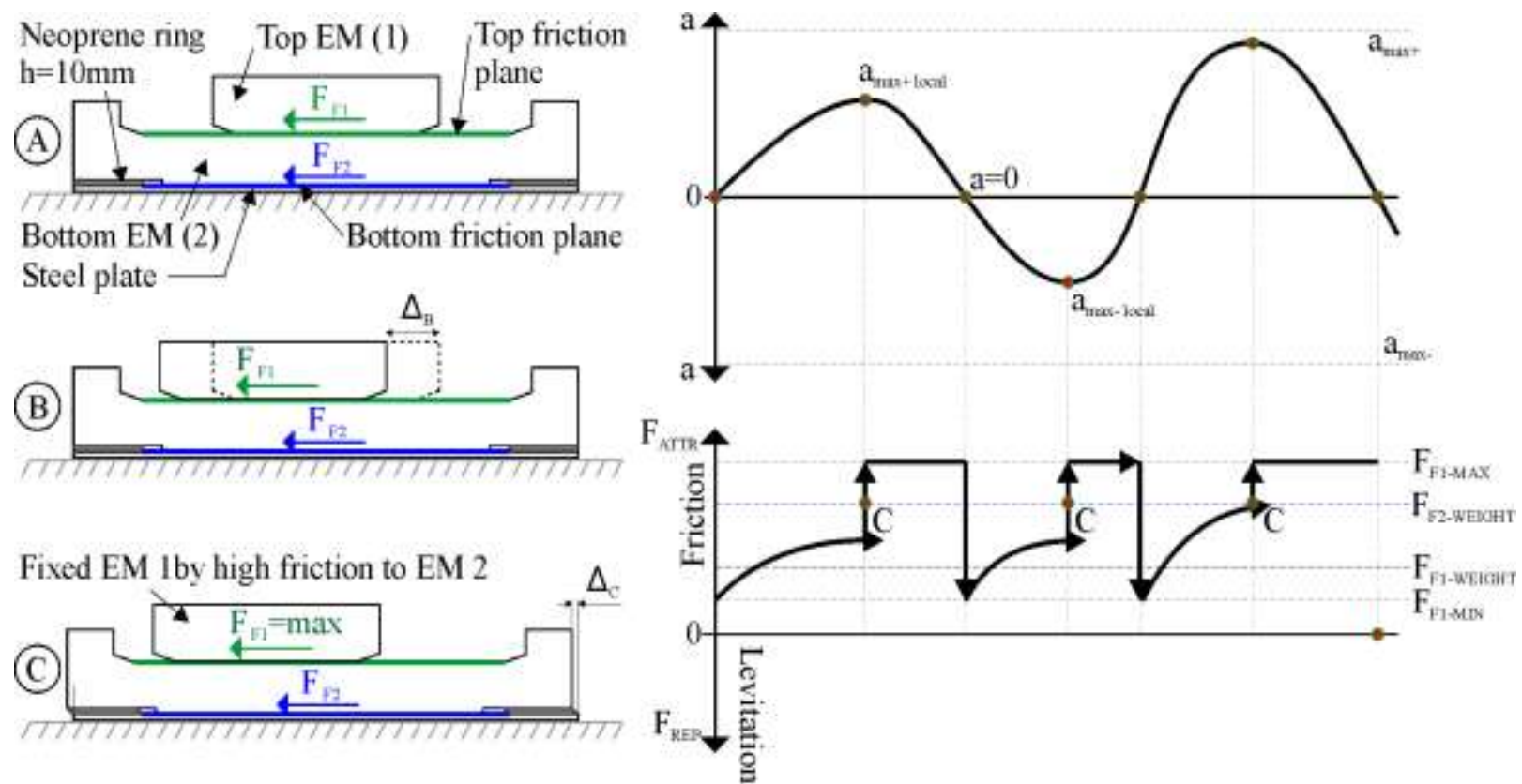

Fixed EM lby high friction to EM 2
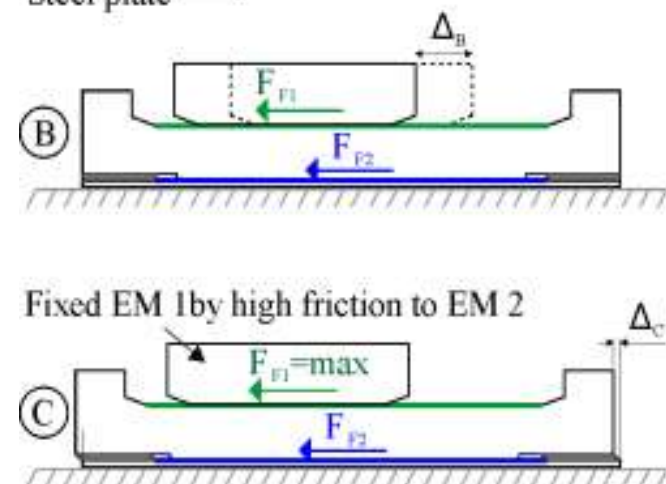

Figure 5. Working steps of proposed seismic isolator

The interpretation of the accelerometer signals can be performed digitally or by using analogic comparators, the last ones having the advantage of faster response but also not utilizing custom integrated circuits that could be out of manufacturing process during the lifetime of a bridge $(50-100)$ years, thus raising difficulties on the maintenance of the automated control circuit. For fast acquisition and transmission of gathered accelerations to the control circuit a minimum $100 \mathrm{~Hz}$ accelerometer is required. 


\section{PARAMETRIC NUMERICAL ANALYSES OF SEISMIC ISOLATOR}

\subsection{Electromagnetic numerical analysis}

The intensity and magnetic field lines are controlled trough variation of voltage and current in electromagnets. An important aspect related to the performance behavior of the two electromagnets is the material from which the electromagnet core is made. The core has a role of gather and concentrate the magnetic field lines thus resulting an intense magnetic flux at the interface between the two electromagnets. For the numerical models a $50 \mathrm{H} 470$ steel was utilized for the core and body case. The magnetization curves and relative magnetic permeability for this type of steel and other materials, are presented below in Figure 6 and Figure 7.

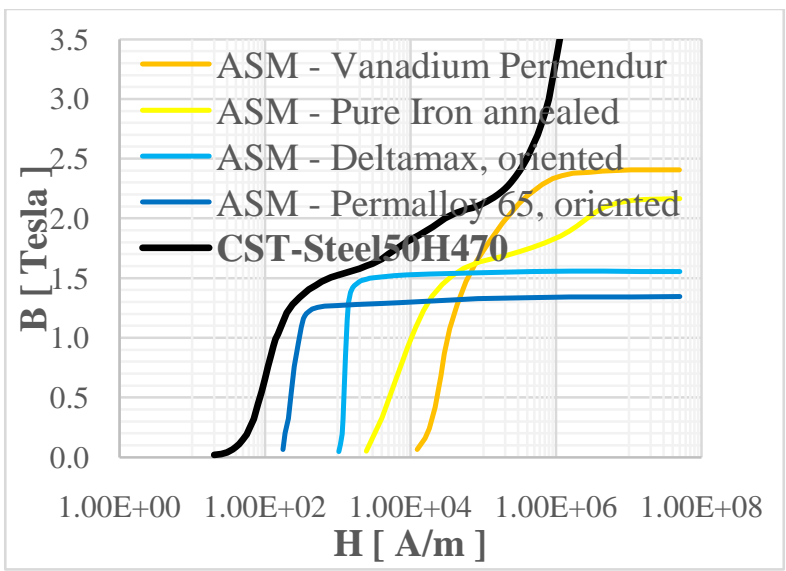

Figure 6. Magnetization curves B-H

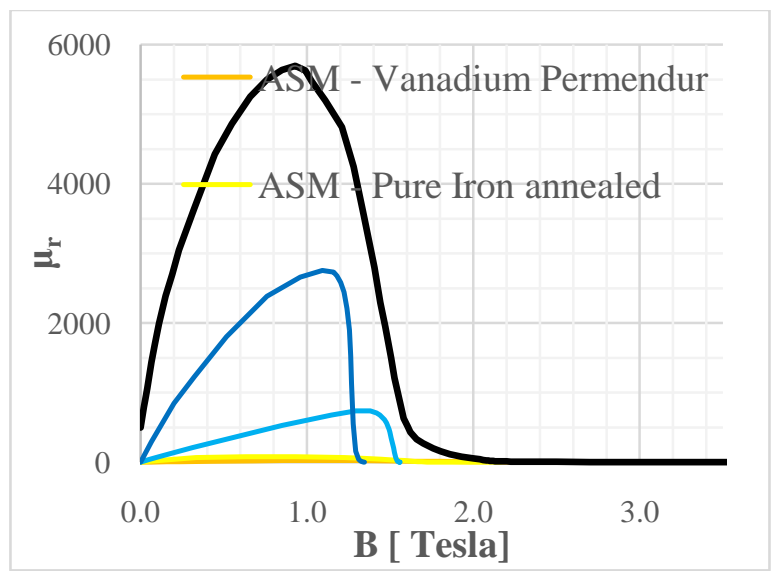

Figure 7. Permeability curves $\mu \mathrm{r}$

Different configurations of the two electromagnets were analyzed (Figure 8) to determine the optimal structural response in both centered position and extreme displaced position. For the parametric analyses, the voltage and current trough electromagnets was varied but also their dimensions, height to width ratio and number of coil turns.
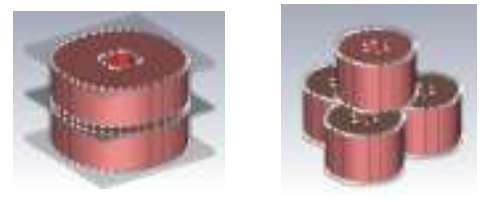

Squared Hexagonal

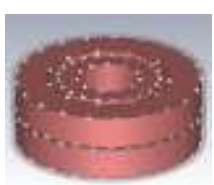

Circular with $2 \& 4$

rings

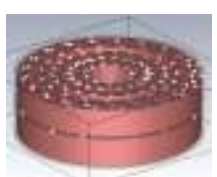

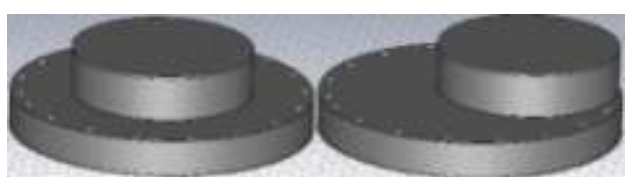

Centered position and maximum eccentricity position

Figure 8. Geometric configurations and relative position of analyzed electromagnets 


\section{ROMANIAN JOURNAL OF TRANSPORT INFRASTRUCTURE}

Silviu Alexandru Constantinescu, Ionuț Radu Răcănel

Seismic isolation of bridges using the principle of electromagnetic attraction and repulsion

The electrical resistivity of coils was computed as a function of temperature, based on a regression function $\rho(t)$, determined from experimental measurements found in [3].

$$
\rho(t)=1.5430428+0.0067406177 \cdot t+1.0688871 \cdot 10^{-7} \cdot t^{2}+9.3349877 \cdot 10^{-10} \cdot t^{3}
$$

Due to high pressure that the electromagnets are subjected during the seismic event, they cannot have a classic coil with circle cross section and requires Bitter discs around the ferromagnetic core.

For the numerical analysis it was chosen a copper alloy with a high elasticity modulus of $208 \mathrm{Gpa}$ while maintaining a low electrical resistivity. The internal structure of the two electromagnets is presented in Figure 9 and final results from the parametric analyses in terms of attraction and repulsion forces are presented in Figure 10.

The intensity distribution of magnetic field lines with the centered electromagnets, can be observed in both states of attraction and repulsion for the middle section (Figure 11).

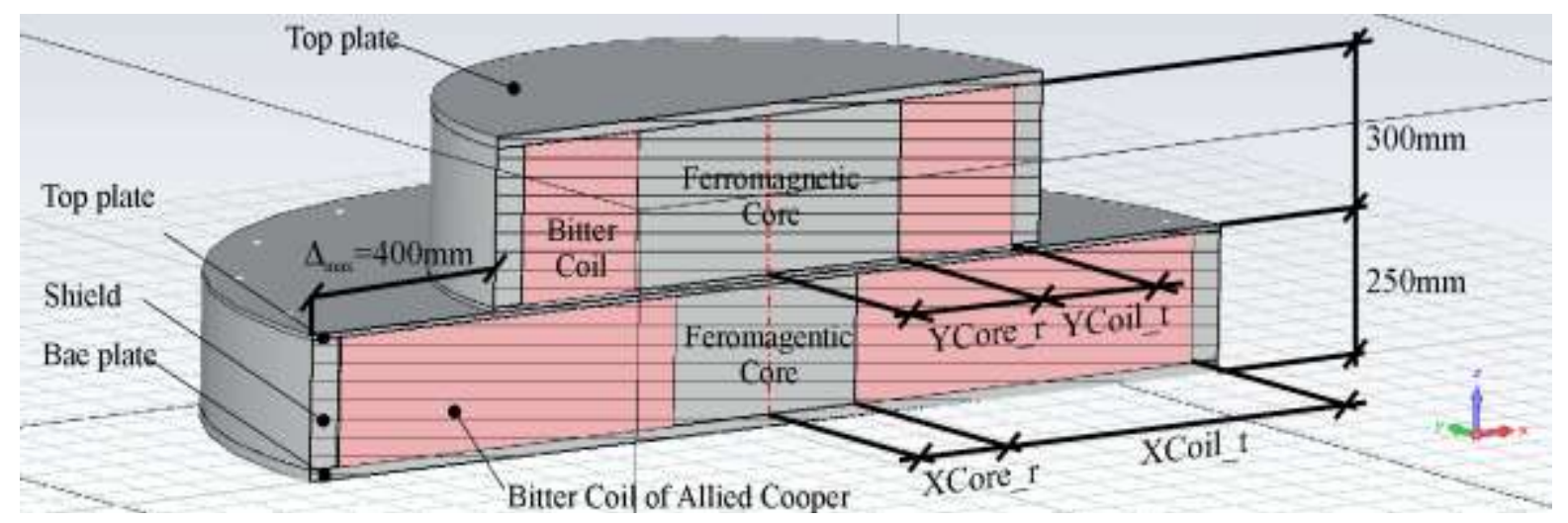

Figure 9. Internal structure of the two electromagnets (half section)
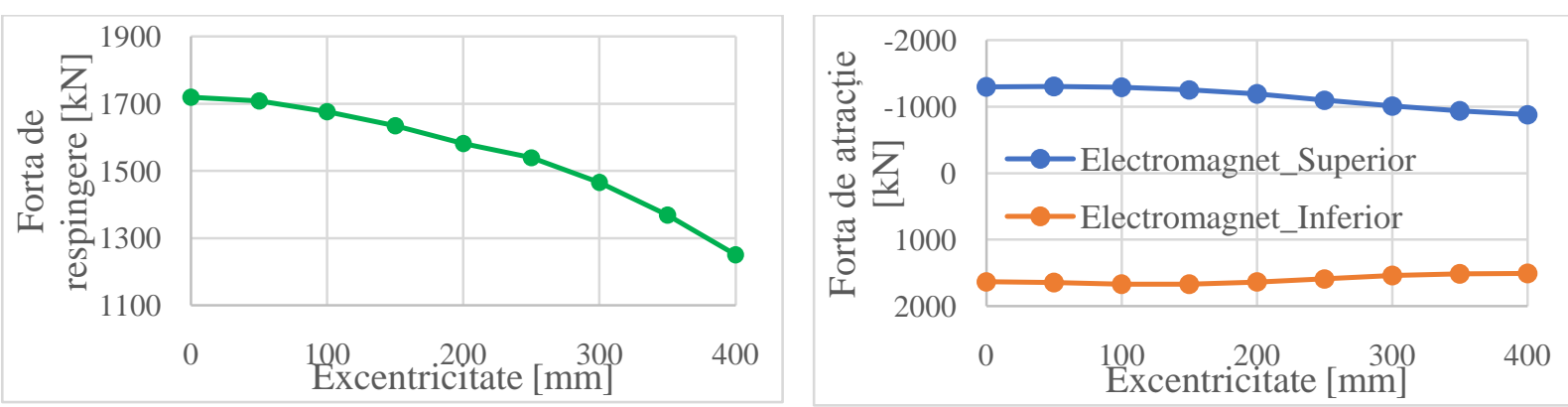

Figure 10. Variation of repelling force (left) and reciprocal attraction force (right) 


\section{ROMANIAN JOURNAL OF TRANSPORT INFRASTRUCTURE}

From thermal analysis it resulted a thermal field with a maximum temperature of $350^{\circ} \mathrm{C}$ at the interface level around ferromagnetic core corners which does not present a problem as the limit at which the steel starts to diminish its Elasticity modulus sits over $400{ }^{\circ} \mathrm{C}$. However, for stronger EM fields it is estimated that an active liquid cooling system is required.
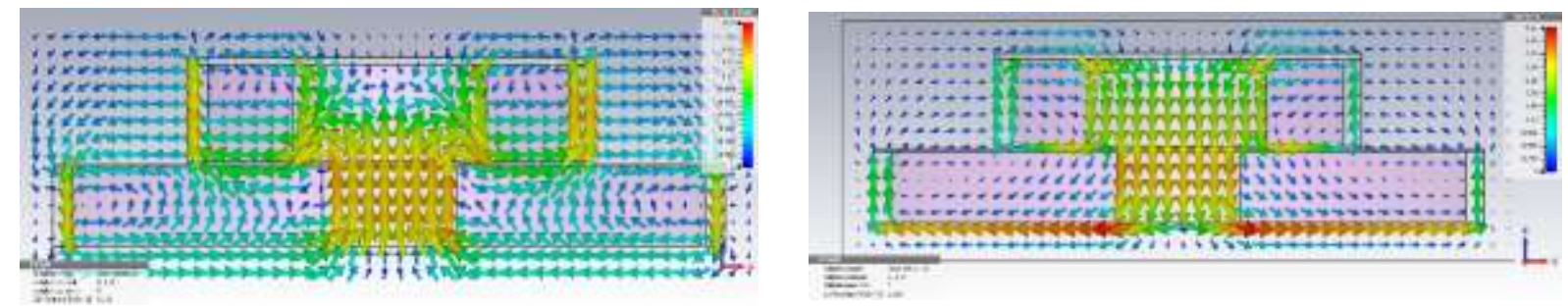

Figure 11. Magnetic flux intensity [Tesla] for repelling (left) and attraction (right)

Final results of physical parameters are presented in Table 1:

Table 1. Geometric and physical parameters obtained for final seismic isolator

\begin{tabular}{|c|c|c|}
\hline Geometric and phvsical parameter & EM2 & EM1 (Mobil) \\
\hline Ambiental temperature [ $\left.{ }^{\circ} \mathrm{C}\right]$ & 40 & 40 \\
\hline Maximum current in coil [Amp] & 2473 & 703 \\
\hline Required voltage [Volts] & 48 & 48 \\
\hline Maximum power [Watt] & 116199 & 34594 \\
\hline Cross section area of copper wire [mm ${ }^{2}$ ] & 706.5 & 200 \\
\hline Number of coil turns [-] & 203 & 296 \\
\hline Equivalent diameter of copper wire [mm] & 30 & 16 \\
\hline Base plate thickness [mm] & 20 & 20 \\
\hline Width of coil section ( Coil t ) [mm] & 740 & 250 \\
\hline Height of coil section / Ferromagnetic core & 220 & 270 \\
\hline Ferromagnetic core radius (Core r) [mm] & 200 & 290 \\
\hline Shield thickness [mm] & 60 & 60 \\
\hline Total height of electromagnet [mm] & 249 & 299 \\
\hline Electromagnet diameter [mm] & 2000 & 1200 \\
\hline Thickness of contact plate [mm] & 9 & 9 \\
\hline
\end{tabular}

\subsection{Time history analysis of seismic isolator}

For this analysis, two 20 second artificial accelerograms were generated. For seismic analysis, only one load model was considered in which the acceleration transversal to bridge (Acc2) was diminished by a factor of $70 \%$ 


\section{ROMANIAN JOURNAL OF TRANSPORT INFRASTRUCTURE}

Silviu Alexandru Constantinescu, Ionuț Radu Răcănel

while the longitudinal acceleration (Acc1) remained unaffected (Figure 12). To verify the accelerograms, the acceleration spectra obtained from artificial accelerograms was compared with design spectra (Figure 13).

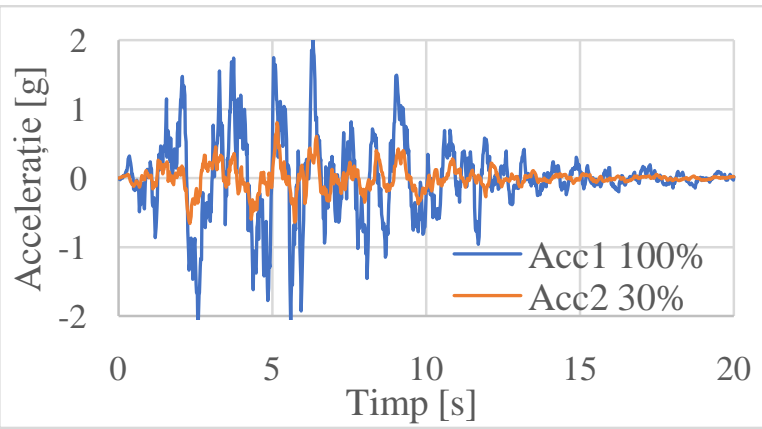

Figure 12. Set $1 \mathrm{~A}$ of accelerations utilized in model (Acc1 100\%, Acc2 $30 \%)$

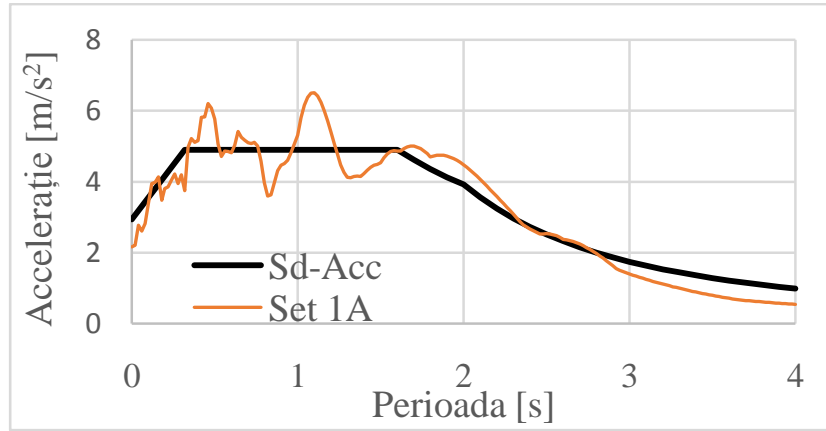

Figure 13. Comparison between resulted spectra in accelerations and design spectra

The time history numerical analysis was performed in ABAQUS, for only one seismic isolator by attaching and uniformly distributing the associated bridge deck mass to the upper electromagnet (EM1). The bridge deck was supported by 6 bearings and its cross section and an isometric view are presented in Figure 14. The bottom electromagnet (EM2) was considered fixed to a column that simulated an abutment and was modeled with $3 \mathrm{~d}$ solid elements at the upper part that were coupled with 1D elements at the bottom part for fast interpretation of cross sectional forces. The column has a diameter of $2 \mathrm{~m}$ and height of $2 \mathrm{~m}$ from which the first top $20 \mathrm{~cm}$ were modelled with solid elements (Figure 15).
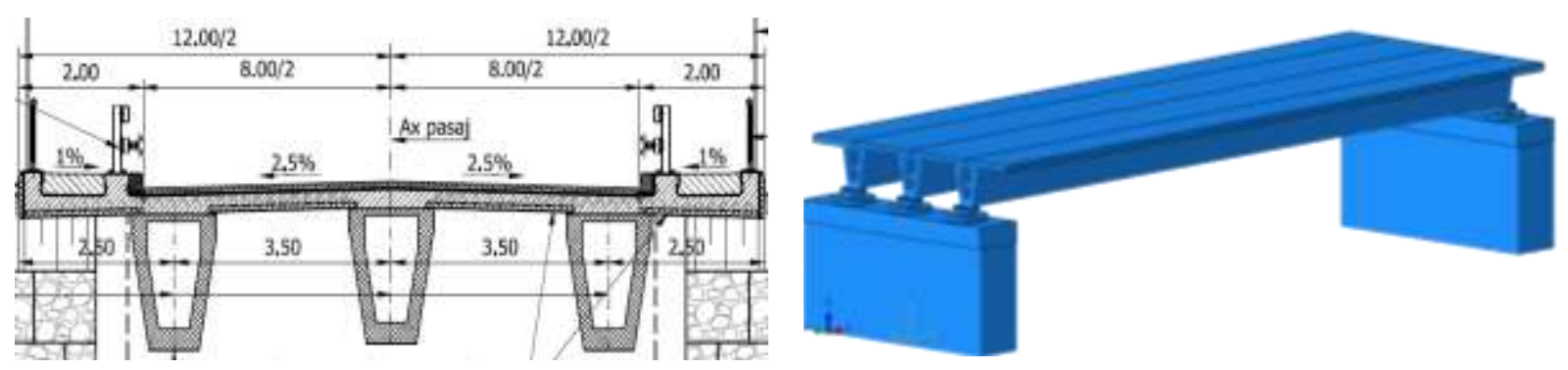

Figure 14. Bridge cross section and isometric view

The 1D-3D coupling of concrete elements was performed by considering the equilibrium at the interface level [6]. The top friction plane had a static friction coefficient of 0.57 and dynamic of 0.40 . For the second friction plane a static friction coefficient of 1.3 and dynamic of 0.9 . For the neoprene ring a Neo-Hooke model was utilized with parameters C10=305.3 and D1=9.75E-5. 


\section{ROMANIAN JOURNAL OF TRANSPORT INFRASTRUCTURE}

Silviu Alexandru Constantinescu, Ionuț Radu Răcănel

For steel $E=210 \mathrm{Gpa}, \mu=0.29$ and $\gamma=7.85 \mathrm{t} / \mathrm{m} 3$. For concrete $\mathrm{E}=40 \mathrm{GPa}, \mu=0.20$ and $\gamma=2.50 \mathrm{t} / \mathrm{m} 3$.

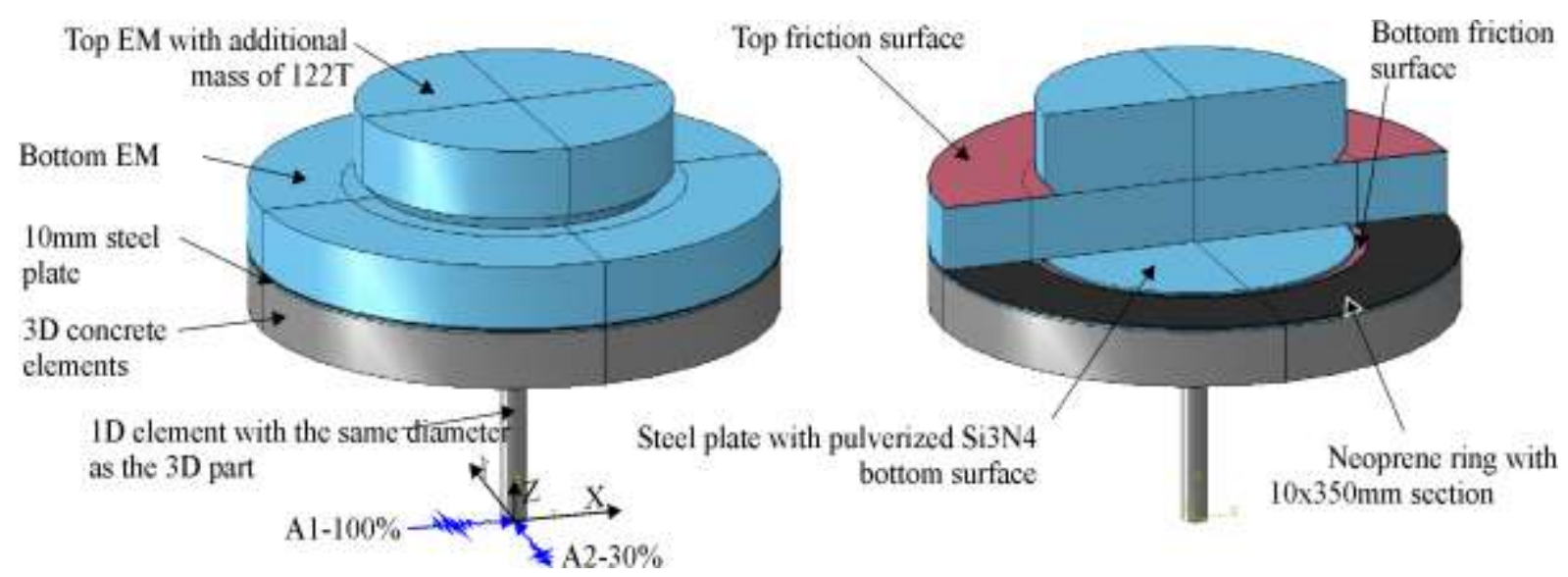

Figure 15. Numerical model utilized for 1 seismic isolator during the analysis

Based on the results from electromagnetic analyses, the maximum repelling force was established at a value of $1200 \mathrm{kN}$ and the attraction force to $1000 \mathrm{kN}$ for each electromagnet. The utilized accelerograms for these analyses was SET 1A from which only the first 10 seconds were used that contained the highest seismic energy. Based on these accelerations, the resultant of $\mathrm{X}$ and $\mathrm{Y}$ accelerations were calculated (Figure 16). Based on resultant accelerations, the required electromagnetic forces were computed (Figure 17).

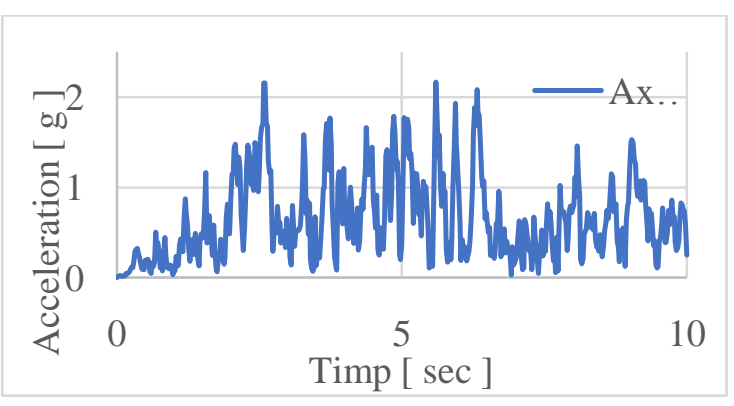

Figure 16. Variation of resultant acceleration in XY plane

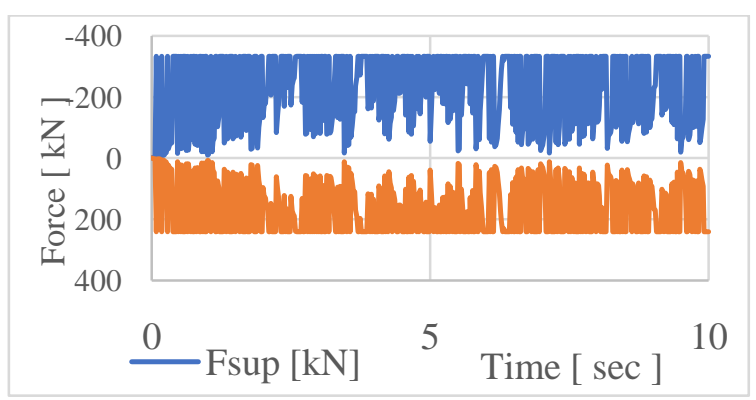

Figure 17. Variation of attraction and repulsion forces for Izo-v6 analysis

During the time history analysis, the relative resultant displacement of the top electromagnet, the shear force along $\mathrm{X}$ axis and the bending moment by the $\mathrm{Y}$ axis were recorded at the base of column. To evaluate the efficiency of the seismic isolator, the last performed analysis (Izo-V6) was compared with three preliminary analyses (I, II and III). 


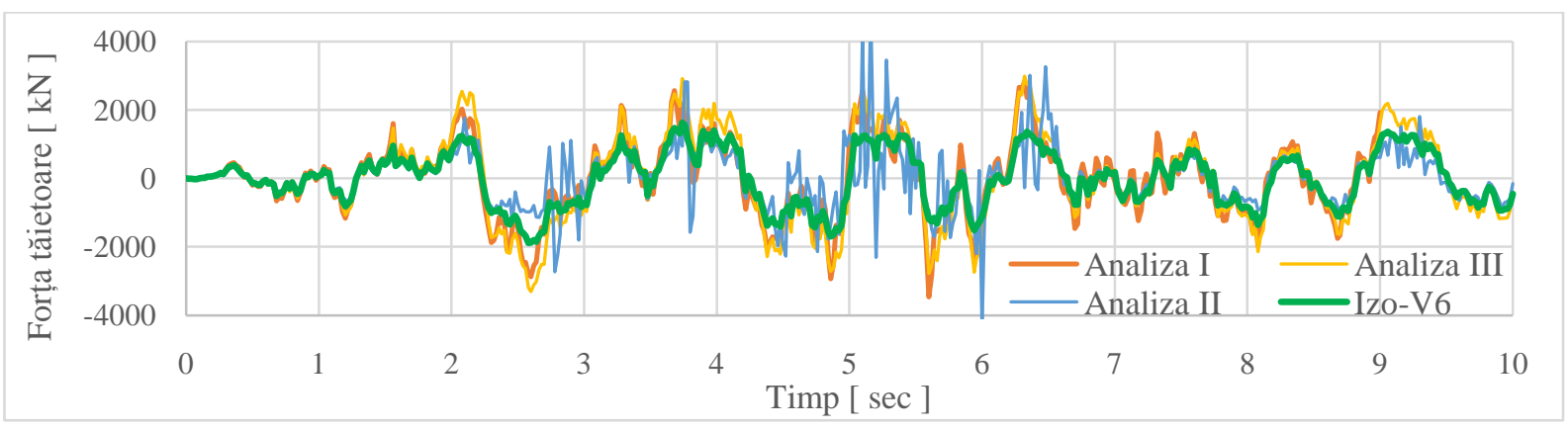

Figure 18. Shear force variation at the base of the column along $\mathrm{X}$ axis

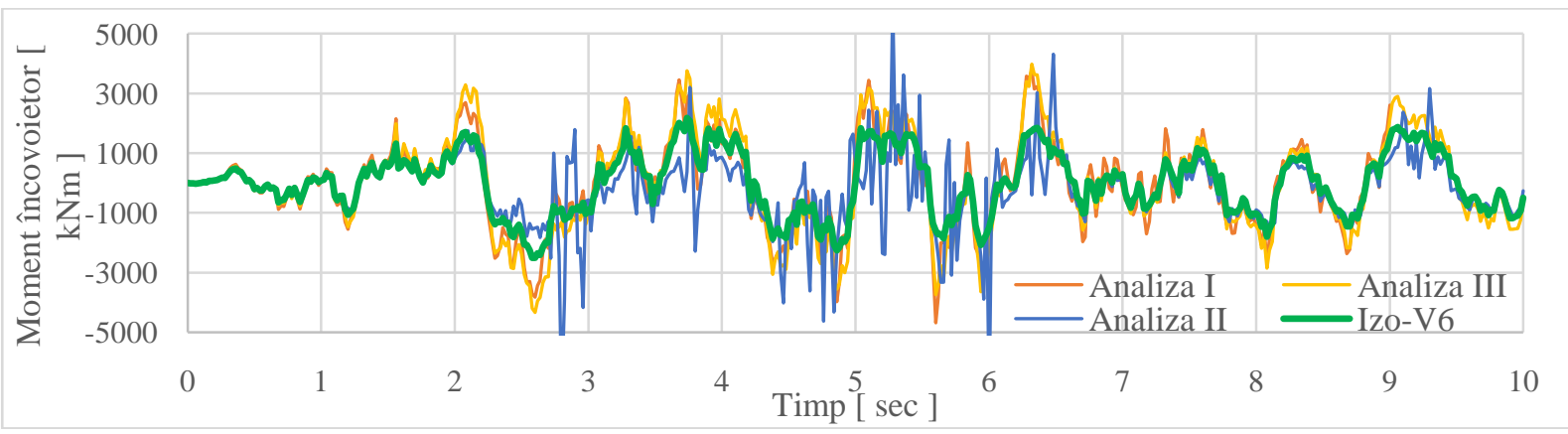

Figure 19. Bending moment variation at the base of the column by the $\mathrm{Y}$ axis

The first preliminary analysis (Analiza I) considered that the top electromagnet (EM1) was fixed to bottom electromagnet (EM2) and the damping and kinetic energy dissipation mechanism composed from the second friction plane and neoprene ring was not introduced in the model.

For the second preliminary analysis (Analiza II), the friction force F1 was controlled but the auxiliary damping and dissipation mechanism was not introduced in the model. The maximum relative recorded displacement was $300 \mathrm{~mm}$ from centered position. In this analysis it was observed that dynamic shocks appeared as consequence of fast friction control and the necessity of introducing the secondary damping and kinetic energy dissipation mechanism.

The third preliminary analysis (Analiza III) considered the top EM1 fixed to EM2 and the secondary damping and dissipation mechanism was introduced. It was observed that by utilizing this configuration the resulting forces on the infrastructure elements cross sections were increased by comparison with the first analysis thus the auxiliary mechanism was not efficient without controlling the friction force at the top friction plane.

Finally, the analysis Izo-V6 considered that the friction force F1 was controlled, by adjusting the attraction and repulsion forces between the two 
electromagnets according to Figure 17. The maximum relative displacement for the top electromagnet and thus the bridge deck was $30 \mathrm{~mm}$ from the centered position.

\section{CONCLUSIONS}

The paper presented a new method for seismic isolation of bridges based on real time friction control between two electromagnets during seismic events. From the point of view of advantages, for the last analysis Izo-V6, the forces on the infrastructure elements cross sections were reduced by a percent between $25 \%$ and $35 \%$, maintaining in the same time small relative displacements of the bridge deck (max $30 \mathrm{~mm})$.

It is worth to mention that this seismic isolator is a custom prototype developed specifically for multiple tests and methods of electromagnetic seismic isolation and its dimensions could be optimized significantly, depending on the admitted maximum relative displacements but also by adjusting the domain of variation for the attracting and repelling electromagnetic forces.

Trough variation of the domain for the attracting and repelling forces it is estimated that a reduction up to $60 \%$ of the forces on the infrastructure elements cross sections could be possible based on results from Analysis II.

By comparison with the passive seismic isolators, this one presents a much higher adaptability to seismic action, without being dependent on the frequency composition of the earthquake or the frequencies of the structure. By utilizing such an isolator, the relative displacement of the bridge deck could be controlled in real time, during a seismic event.

Another important aspect is the system's ability to auto-calibrate by estimating the maximum possible acceleration based on site seismic characteristics and primary seismic waves that reach the structure. The system could also re-center the top electromagnets and thus bring the bridge in its original position before earthquake by bringing the electromagnets in a quasilevitation state and utilizing secondary low power electromagnets that can offer the horizontal forces required for re-centering the isolator.

The performances of such a system comes also with some disadvantages by comparison with passive classical methods. The initial high cost due to relative new technologies and performant materials required, from a mechanical, magnetic and electric point of view. Such an isolator requires a connection to a power network or solar panels. Even if the rechargeable batteries must deploy a high current for a short period of time, they must have a long-life span in fully 


\section{ROMANIAN JOURNAL OF TRANSPORT INFRASTRUCTURE}

Silviu Alexandru Constantinescu, Ionuț Radu Răcănel

Seismic isolation of bridges using the principle of electromagnetic attraction and repulsion

load regime. The last disadvantage would be the increased maintenance required for such a system by comparison with current passive devices.

\section{REFERENCES}

[1]. S. USUBA, R.B. HEIMANN: "Dense $\mathrm{Si}_{3} \mathrm{~N}_{4}$ Coatings with High Friction Coefficient Deposited by High-Velocity Pulsed Plasma Spraying", Journal of Thermal Spray Technology, Volume 15(3) September 2006

[2] AMERICAN SOCIETY FOR METALS: „Metals Handbook”, 8th edition, Vol. 1, p792, 1966

[3]. R.A. MATULA: „Electrical Resistivity of Copper, Gold, Palladium and Silver” J. Phys. Chem. Ref. Data, Vol. 8, No. 4, 1979

[4]. U.T.C.B.: „Cod de Proiectare Seismică P100-1”, 2013

[5]. G. RODOLFO SARAGONI, GARY C. HART: „Simulation of Artificial arthquakes”, Earthquake Engineering \& Structural Dynamics, Vol. 2, Issue 3, pages 249-267, 1973

[6]. R.W. McCune, C. G. ARMSTRONG, D.J. ROBINSON: „Mixed Dimensional Coupling in Finite Element Models", Int. Journal for Numerical Methods in Engineering, Vol 49 pp. 725-750, 2000

[7]. DASSAULT SYSTEMES: „Abaqus Analysis User's Guide”, 2012

[8]. COMPUTER SIMULATION TECHNOLOGY: „CST EM Studio Manual”, 2012

[9]. FARZAD NAEIM, JAMES M. KELLY: „Design of Seismic Isolated Structures From Theory to practice", John Wiley\&Sons, Inc.,N.Y., 1999

[11]. SR-EN 1998-2: „Design of Structures for Earthquake Resistance. Part 2:Bridges”, Eurocodes, 2006

[12]. GARG ANUPAM KUMAR: „Classical Electromagnetism in a Nutshell”, Princeton University Press, 2012

[13]. ASM: „Properties and Selection: Iron, Steels and High Performance Alloys”, ASM International Handbook Committee, USA, 2005 